\title{
Hylan G-F20 and galactomannan joint flares are associated to acute synovitis and release of inflammatory cytokines
}

\author{
Rodolfo de Melo Nunes', Pablyana Leila Rodrigues Cunha², Ana Carolina Matias Dinelly Pinto', \\ Virgínia Claudia Carneiro Girão ${ }^{3}$, Judith Pessoa de Andrade Feitosa ${ }^{2}$ and Francisco Airton Castro Rocha ${ }^{1 *}$ (D)
}

\begin{abstract}
Background: Injection of Hylan G-F20 (HY) into joints may provoke local flares, which mechanisms may involve reaction to protein contaminants. We have previously developed a protein-free saline-soluble galactomannan derived from guar gum (GM) that displays both analgesia and chondroprotection in experimental osteoarthritis $(\mathrm{OA})$. We now demonstrate that both GM and Hylan G-F2O (HY) promote mild synovitis with cytokine release after intra-articular injection.

Methods: Mice received $100 \mu \mathrm{g} / 25 \mathrm{\mu L}$ GM or HY or saline into the knees. Joint pain was evaluated using von Frey test; cell influx, interleukin (IL)-1, IL-6, and CXCL-1 (pg/mL) levels were assessed in joint lavage at $6 \mathrm{~h}$. Synovia were excised for histopathology.

Results: Neither GM nor HY after being given into mice knee joints induced pain albeit promoting mild cell influx into joint washings as well as mild synovitis at histology, with no damage to the underlying cartilage. HY but not GM promoted IL-1 release into mice joints. Both compounds induced IL-6 and CXCL-1 release.

Conclusion: Intra-articular injection of HY or GM promote acute transient synovitis whilst not provoking detectable significant joint damage. Local administration of these polysaccharides induces acute intra-articular release of inflammatory cytokines, which may account for joint flares following viscosupplementation.
\end{abstract}

Keywords: Galactomannans, Hyaluronic acid, Hylan G-F20, Osteoarthritis, Polysaccharides, Viscosupplementation

\section{Background}

Viscosupplementation is a commercially available safe alternative to treat osteoarthritis (OA). Such nonsurgical treatment aims to restore viscoelastic properties in diarthrodial joint cavities by injecting viscous hyaluronic acid formulations intra-articularly [1-4].

There are claims that high molecular weight viscosupplements provide better results, but definitive data to prove this assumption are yet to be obtained $[5,6]$. Actually, high molar mass hylans (around $10^{6} \mathrm{~g} / \mathrm{mol}$ ) had similar efficacy, as compared to low molar mass

\footnotetext{
*Correspondence: arocha@ufc.br

1 Departamento de Medicina Interna da Faculdade de Medicina da

Universidade Federal do Ceará, Fortaleza, Ceará, Brazil

Full list of author information is available at the end of the article
}

compounds $\left(5-7.5 \times 10^{5} \mathrm{~g} / \mathrm{mol}\right)$ in providing pain relief in OA [7]. The intra-articular half-life of viscosupplements is assumed to be around $24 \mathrm{~h}$ but patients may experience up to 6 months of pain relief following a single injection, suggesting that rheological properties may not be the only explanation of the therapeutic benefit [ 1 , $7,8]$. Serious adverse reactions following viscosupplementation are uncommon. Reports of local pain following injection vary from 1 to $33 \%$ of the patients and up to $3 \%$ experience a pseudoseptic reaction, with joint swelling and intense pain $[9,10]$. High molar mass compounds were more frequently associated to local flares. Reasons for this pseudoseptic reaction are ascribed to immune sensitization since they usually occur after a first injection but their occurrence following a single

(c) The Author(s). 2020 Open Access This article is licensed under a Creative Commons Attribution 4.0 International License, which permits use, sharing, adaptation, distribution and reproduction in any medium or format, as long as you give appropriate credit to the original author(s) and the source, provide a link to the Creative Commons licence, and indicate if changes were made. The images or other third party material in this article are included in the article's Creative Commons licence, unless indicated otherwise in a credit line to the material. If material is not included in the article's Creative Commons licence and your intended use is not permitted by statutory regulation or exceeds the permitted use, you will need to obtain permission directly from the copyright holder. To view a copy of this licence, visit http://creativecommons.org/licenses/by/4.0/. 
injection questions this assumption $[1,10]$. Due to ethical reasons, it is hard to demonstrate whether viscosupplementation compounds promote synovitis after injection into human healthy joints. In naive rabbits subjected to an air pouch model, viscosupplements induced a moderate inflammatory reaction and a mild chronic granulomatous reaction following injection into the knee joint [11].

Viscosupplements are primarily made of polysaccharides, but Hylan G-F20 (HY), the most commonly used compound that is isolated from rooster combs, also contains avian protein contaminants [1]. We have previously hypothesized that the polysaccharide structure rather than its rheology could explain the pain relief provided by viscosupplementation agents. Using a commercially available guar gum, a polysaccharide extracted from Cyamopsis tetragonolobus, composed of a galactomannan (GM) with a long central chain of mannose residues, we isolated a protein-free GM, which we use as a salinesoluble polysaccharide that is 40 times less viscous than HY [12]. Injection of this GM into the knee of rats subjected to experimental OA provided analgesia similar to that of HY regardless of using a viscous or a salinesoluble GM formulation, showing that viscosupplementation benefits may not depend on the viscoelastic properties [13]. We also showed that chronic GM administration prevented joint damage in an OA model and structure modifications of GM abrogate the therapeutic benefit [14].

Although unproven, protein contaminants and the viscous nature of viscosupplements may favor the development of local reactions, particularly when made blindly into joints. Spillage of injected compounds into perisynovial tissues could at least partially be responsible for local reactions [9]. Easy-to-handle, saline soluble, protein-free formulations could thus be a better alternative to current viscosupplements.

We now show that HY as well as a GM solution induce mild acute transient painless synovial cell influx into mice joints that is associated with cytokine release.

\section{Methods}

\section{Polysaccharides}

Guar gum was purchased from Sigma-Aldrich, São Paulo, Brazil and purified as described previously [12]. Hylan G-F20 (Synvisc ${ }^{\circ}$ ) was purchased from Novartis ${ }^{\circ}$, São Paulo, Brazil.

\section{Animals}

A total of 54 Swiss mice of either sex (25-30 g) were provided by the central animal house of our Institution. Animals were housed in cages (6 / cage) in temperaturecontrolled rooms with a $12 \mathrm{~h}$ light/dark cycle with free access to water and food. At the start of any experiments, mice were 2.5 months of age. All animal procedures and experimental protocols were approved by our local ethics committee on animal experimentation, that follows the recommendations of the Brazilian Council on Animal Experimentation (CONCEA) (protocol number 113/07). All efforts were made to minimize animal suffering and the number of animals used.

\section{Intra-articular injection}

Mice were anesthetized with i.m. ketamine $(50 \mathrm{mg} / \mathrm{kg})$ and xylazine $(10 \mathrm{mg} / \mathrm{kg})$. After local asepsia, animals received either sterile $100 \mu \mathrm{g} / 25 \mu \mathrm{L}$ HY or GM (solution) or $25 \mu \mathrm{L}$ saline intra-articular (i.art.) injections.

\section{Assessment of pain behavior}

Nociceptive behavior (regarded as joint pain) was assessed using the electronic pressure-meter nociception paw test by an observer blinded to group allocation [15]. Animals were placed in acrylic cages $(12 \times 10 \times 17 \mathrm{~cm}$ high) with a wire grid floor, $15 \mathrm{~min}$ before the beginning of the tests, in a quiet room. Stimulations were performed only when animals were quiet, without exploratory, urination or defecation movements and not resting on their paws. The electronic pressure-meter consists of a hand-held force transducer fitted with a polypropylene tip (Electronic von Frey aesthesiometer, Insight Equipamentos Científicos Ltda., Brasil). The polypropylene tip was applied perpendicularly to one of the five distal footpads of the right hind paw. The intensity of the stimulus was automatically recorded when the paw was withdrawn. The test was repeated three times, until less than a $1 \mathrm{~g}$ difference between measurements was obtained. Results were expressed as the mean value of three withdrawal threshold measurements (g).

\section{Assessment of cell influx and inflammatory mediators in joint aspirates}

Groups of animals were sacrificed $6 \mathrm{~h}$ following intraarticular injection with exsanguination, under terminal anesthesia. The synovial cavity of the knee joints was washed with $0.05 \mathrm{~mL}$ saline containing $10 \mathrm{mmol} / \mathrm{L}$ EDTA. The synovial fluids were collected by aspiration and total cell counts were performed using a Neubauer chamber. Differential cell counts were performed using the panoptic Instant Prov $^{\mathrm{mm}}$ staining kit (New ProvBrasil $\left.^{\text {Tn}}\right)$. Cell influx will be used when referring to cell counts in joint exudates. After centrifuging $(500 \mathrm{~g} / 10$ $\mathrm{min})$, the supernatants, collected at $6 \mathrm{~h}$ following intraarticular injections, were stored at $-80^{\circ} \mathrm{C}$ until used for measuring the concentrations of Interleukin (IL)-1, IL-6 and CXCL1 using commercially available kits ( R \& D Systems, São Paulo, Brazil). 


\section{Histopathology}

The same groups of animals used for cell counts (sacrificed $6 \mathrm{~h}$ after intra-articular injection) had their joint tissues excised for the histological study. Other groups were sacrificed with exsanguination, also under terminal anesthesia, 7 or 28 days following intra-articular injection and were also used for histological study. After fixation in $10 \% \mathrm{v} / \mathrm{v}$ formaldehyde solution and decalcification $(5 \% \mathrm{v} / \mathrm{v}$ formic acid in $10 \% \mathrm{v} / \mathrm{v}$ formaldehyde solution), the whole joint, comprising the distal femoral and proximal tibial extremities, was processed for paraffin-embedding and staining with hematoxylin-eosin (HE) and safranin-O. Analysis was expressed as one result for each sample. Semi-quantitative histopathological evaluations was performed by an independent observer (VCCG) blinded to group allocation considering synovial proliferation and cell infiltration, meaning a semiquantitative evaluation of cells present in the synovial tissue, ranging from 0 to 3 (0, absent, 1, mild; 2, moderate; 3 , severe). Results are expressed as the median (IQR) value for each group of six animals.

\section{Statistical analysis}

Results are presented as means $\pm 95 \%$ C.I. for pain behaviour and cell counts in joint washings or medians (IQR) for histology of measurements made on at least six animals in each group. Assessment of normality of the pain behaviour data was done using the D'AgostinoPearson Omnibus test. Differences between means and medians were compared using Student's t-test or Kruskal-Wallis test, respectively; $P<0.05$ was considered as significant.

\section{Results}

Cell migration and hypernociception

Figure 1a shows that GM or HY induced a mild transient though significant cell influx at $6 \mathrm{~h}$ that subsided after $24 \mathrm{~h}$, as compared to saline injection. Cell counts measured at 7 or 28 days did not differ from those at 24 h. Polymorphonuclear neutrophils were predominant in the cell exudates at $6 \mathrm{~h}(>85 \%)$ in both $\mathrm{HY}$ and GM injected joints whereas there were only mononuclear cells in the saline group at this time-point. Joint washing collected at 7 or 28 days in all groups were composed
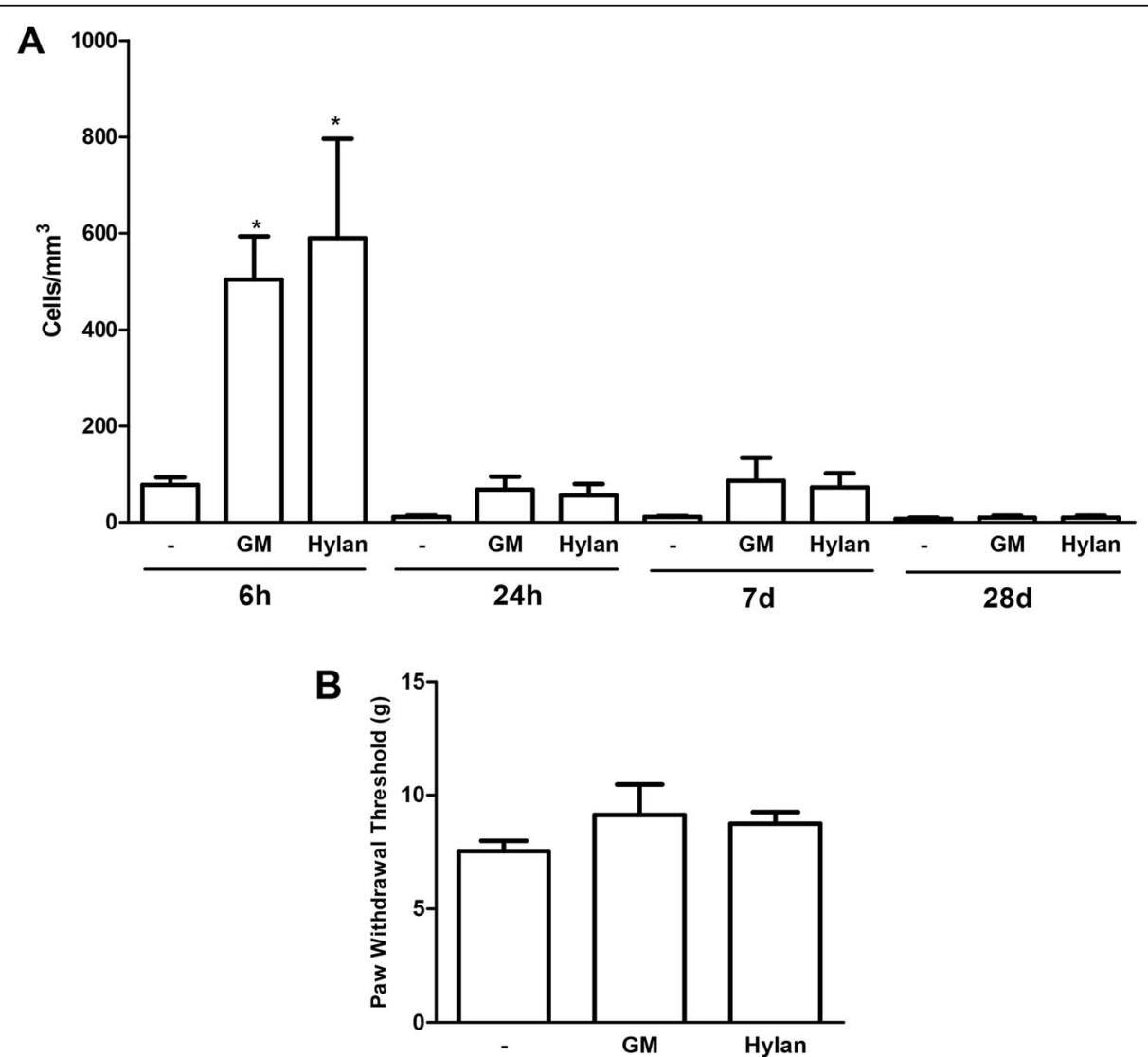

Fig. 1 Guar gum (GM) or Hylan G-F20 (HY) $(100 \mu \mathrm{g} / 25 \mu \mathrm{L})$ or $25 \mu \mathrm{L}$ saline were injected into naïve mouse joints; a kinetics of total leukocyte counts in joint lavage; $\mathbf{b}$ Joint pain evaluated at $5 \mathrm{~h}$ post-injection, using von Frey test. Data are mean \pm SD of $n=6 /$ group; one-way ANOVA followed by Tukey's test 
solely of mononuclear cells. Despite the increase in acute cell influx, no hypernociceptive response could be demonstrated in joints that received HY or GM, as compared to control (Fig. 1b).

\section{Synovitis}

The histopathological appearance of the synovia of mice subjected to GM or HY i.art. Injection is illustrated in Fig. 2 showing synovial proliferation and cell infiltration starting at $24 \mathrm{~h}$ that could also be seen at 7 and 28 days. Synovia excised at $6 \mathrm{~h}$ following injection of either $\mathrm{HY}$ or GM to joints had no demonstrable changes, as compared to control. Detailed histological analysis of the samples in the various time points ( $24 \mathrm{~h}, 7$ and 28 days) shown in Fig. 2 also reveal the mild character of the synovitis particularly in the long term. Cell infiltration into the synovia, meaning presence of polymorphonuclear neutrophils, lymphocytes, and macrophages was mild and did not differ between HY and GM groups. Similarly, synovial proliferation did not differ between HY and GM groups, although being significantly higher as compared to saline-injected joints. There were no samples with areas of granuloma or giant cells formation revealing the mild synovitis seen following intra-articular injection of either HY or GM. There were no alterations in the cartilage or subchondral bone that could be demonstrated in the hematoxylin-eosin and safranin-O stained material (data not shown). Therefore, at least under light microscopy, no structural damage, despite the above-mentioned synovitis, could be associated to the compounds.

\section{Levels of inflammatory mediators in joint lavage}

Table 1 shows an almost three-fold increase in IL-1 level in HY-injected joints whereas IL-1 levels did not increase in GM-injected joints, as compared to control. Remarkably, there was an over 20-fold increase in IL-6 levels in the joints of mice that received either GM or HY, as compared to control. Levels of the chemokine CXCL-1 displayed a 6-fold or 12-fold increase in joints that received HY or GM, respectively, as compared to saline-injected joints.

\section{Discussion}

We have previously shown that there is no detectable nitrogen in our isolated GM leading us to consider it a protein-free compound [12] bearing an average molar mass $(\mathrm{Mw})$ of $3.9 \times 10^{6} \mathrm{~g} / \mathrm{mol}$ [14]. HY is a mixture of hylan A and hylan B with an average molar mass of approximately $6.0 \times 10^{6} \mathrm{~g} / \mathrm{mol}$, being a hydrated gel that contains small amounts of avian proteins (http://products.sanofi.ca/en/synvisc-information-for-use.pdf).

We have recently shown that our protein-free GM formulation does also provide chondroprotection in experimental OA. In that study, rats received 9 weekly injections of GM and did not appear to develop systemic adverse effects [14]. In the present report, the cell influx into the washings of mice knee joints following GM or $\mathrm{HY}$ injection subsides at $24 \mathrm{~h}$ being no longer detected at 14 or 21 days (data not shown).

Previous reports have shown that viscosupplementation agents may induce severe joint pain, sometimes pseudoseptic, but the mechanistic is yet to be described. Inadvertent injection into the surrounding joint tissues rather than exclusively inside the joint space has been suggested to provoke those reactions [9]. Thus, guided imaging is currently recommended when performing joint injections in humans, but into the knee, in order to avoid those pseudoseptic flares [1]. There can be a mild, painful flare in the joint that disappears within $48 \mathrm{~h}$ following injection, but sometimes severe reactions take place [16].

We cannot completely rule out some spillage into perisynovial tissue in our experiments. However, the mild and transient cell influx seen in the present study, despite the small joint size, likely results from the careful joint injection, trying to be sure that compounds were solely, or at least predominantly, injected inside the joint. Despite the acute cell influx into joint cavities, neither GM nor HY elicited joint pain to mouse joints, which is similar to what we reported with both compounds in a rat study [13]. We did not evaluate the effect of repeated administrations in the present study since the size of mice joints represents a limitation. It is worth mentioning though that $\mathrm{HY}$ is marketed to be used as a single injection of a $6 \mathrm{~mL}$ gel formulation and in our hands GM and HY dosages were comparable regarding analgesia in experimental OA [13].

Using an air-pouch model, it was previously shown that $\mathrm{HY}$ induced granuloma formation and fibrosis. On the other hand, when injected into rabbit knees, those changes were milder [11]. Although the air-pouch model is a classic tool to evaluate inflammation, singularities of the synovial cavity might explain the more pronounced inflammation in the former. The synovial tissue has a rich blood supply. Vascular permeability and blood flow increase during inflammation thus increasing the already fast clearance rate in this tissue. In the present study, species differences as well as different dosing might have influenced the apparently less severe synovitis seen. As expected, there were no alterations in cartilage or in the subchondral bone. We are not aware of previous studies that have shown such a result, but it is worth mentioning since it adds to the safety profile of viscosupplementation agents, demonstrating absence of relevant chronic synovitis and joint damage provoked by the compounds.

Our data showed that mouse joints that received HY had a remarkable increase in IL- $1 \beta$ levels. We are not 

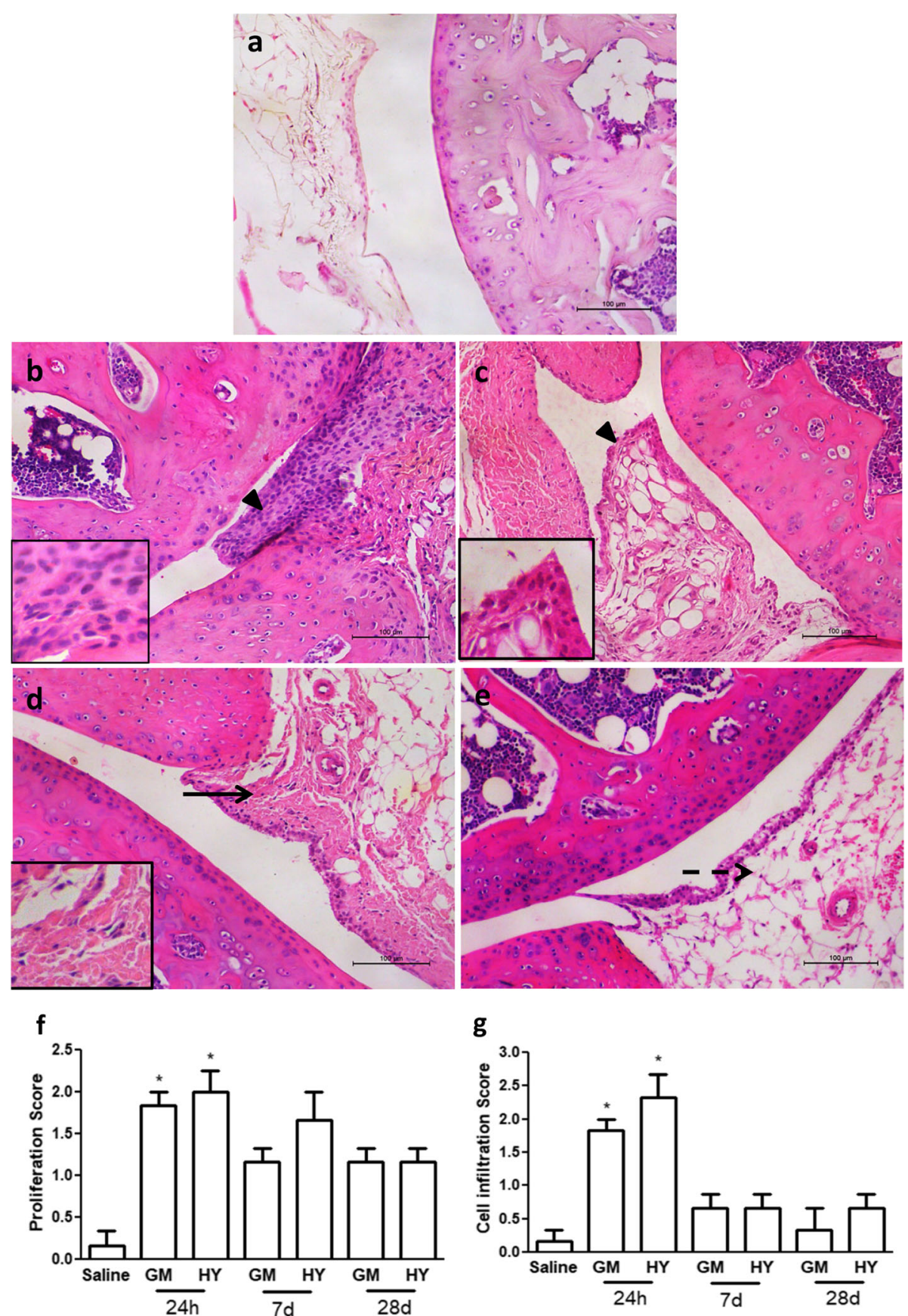

Fig. 2 Representative illustration of the histopathology of mice knees after injection of guar gum (GM) or Hylan G-F20 (HY) (100 $\mu \mathrm{g} / 25 \mu \mathrm{L})$ or saline into naive joints and analysis of histopathology scores. Knee joints were excised after 7 or 28 days and processed for hematoxylin-eosin staining. Saline-injected joints appear normal (a); there is mild synovial hyperplasia (arrow-heads) in GM and HY-injected joints at 7 days (b and c, respectively; insets); at 28 days, there is no long synovial hyperplasia with mild fibrosis in HY (d, arrow; inset) with apparently normal fat subsynovial tissue in a GMinjected joint (e, dashed arrow) (Original magnification $\times 200$ ). Proliferation of synovial cells $(\mathbf{f})$ and cell influx $(\mathbf{g})$ into the synovia were evaluated under optical microscopy using HE and Safranin-O staining. Data are medians (IQR) of $n=6 /$ group; ${ }^{*} p<0.05$ using Kruskal-Wallys test

aware of previous data showing that $\mathrm{HY}$ or any other viscosupplementation agent induces in vivo IL-1 $\beta$ release. This major inflammatory cytokine has been associated to catabolic effects in joints affected by OA as well as in other inflammatory arthropathies [17]. Actually, intra-articular hyaluronic acid treatment was shown to decrease IL-1 $\beta$ levels both in experimental models and human OA [18]. As opposed to HY, GM injection did 
Table 1 Levels of inflammatory mediators following injection of a galactomannan (GM) or Hylan G-F20 (HY) into mouse joints

\begin{tabular}{llll}
\hline Group & $\mathrm{IL}-1 \beta$ & $\mathrm{IL}-6$ & $\mathrm{CXCL}-1$ \\
\hline Control & $16.30 \pm 1.694$ & $25.39 \pm 11.56$ & $23.88 \pm 1.125$ \\
HY & $47.57 \pm 12.60^{*}$ & $542.9 \pm 303.4^{*}$ & $144.0 \pm 33.35^{*}$ \\
GM & $11.43 \pm 4.154$ & $617.9 \pm 262.6^{*}$ & $288.0 \pm 58.65^{*}$
\end{tabular}

Mice received GM, HY or saline into the knee. Interleukin (IL)-1, IL-6 and CXCL$1(\mathrm{pg} / \mathrm{mL})$ levels were measured in joint washings after $6 \mathrm{~h}$. Data are mean \pm SD of $n=6 /$ group; * $p<0.05$ using one-way ANOVA followed by Tukey's test

not induce IL-1 $\beta$ release whereas IL-6 and CXCL1 levels were greatly increased following injection of either of the compounds. IL- 6 induces the production of Creactive protein, an inflammatory marker that is associated to a systemic inflammatory state leading to morning stiffness and fever [19]. Humans subjected to viscosupplementation that developed flares with pseudoseptic reactions were shown to have increase in erythrocyte sedimentation rate as well as in C-reactive protein levels $[9,10]$. Cytokine release in our hands was detected as early as $6 \mathrm{~h}$ following injection of the compounds. Neutrophils, which are not relevant sources of cytokine production, represent the major cell component in joint exudate at this time. Hence, we speculate that resident cells, possibly synoviocytes, stimulated by the injection of GM or HY, are producing those mediators.

We are not aware of any previous demonstration of IL-6 or CXCL1 chemokine (a neutrophil chemoattractant) release following the administration of viscosupplements [20]. Indeed, although increase in IL-1 levels following $\mathrm{HY}$ injection was comparably mild, those of IL- 6 and CXCL1 were very prominent. This unexpected release could be linked to the local inflammatory flares mentioned in some patients after receiving joint injection of such compounds. Increase in joint CXCL1 levels may also at least partially explain the acute migration of neutrophils. Discussing the inflammatory role of these cytokines in chronic arthropathies is beyond our present scope, but we should emphasize that, to the best of our knowledge, this is the first demonstration that a viscosupplementation agent and a galactomannan, shown to be analgesic and chondroprotective in an OA model [14], paradoxically induce a mild local inflammatory synovitis that is associated with cytokine release. Guar gum has proven to be a safe compound over a wide dose range [21] and HY safety has not been an issue of major concern [1]. However, though unlikely, the release of cytokines could be associated to systemic rare adverse effects given the rich blood supply and fast clearance characteristic of the synovial membrane thus driving compounds into the systemic circulation.

\section{Conclusion}

Our data demonstrate that HY and GM induce mild synovitis when injected into naive mice joints that is associated with the release of inflammatory cytokines. We believe this may account for local flares following injection of viscosupplements into human joints.

\section{Abbreviations}

HY: Hylan G-F20; IL: Interleukin; GM: Galactomannan; OA: Osteoarthritis

\section{Acknowledgements}

we acknowledge partial support of this work from CNPq (grant 308429/ 2018-4).

\section{Authors' contributions}

RML, VCCG, JPAF, FACR contributed in the conception of the protocol; RML, ACMDP, VCCG, FACR performed animal studies, including histology reading (VCCG); RML, VCCG, PLRC, JPAF, FACR wrote the manuscript; all authors revised and approved final version of the manuscript.

\section{Funding}

No specific funding was obtained for this study.

\section{Availability of data and materials}

All data generated or analysed during this study are included in this published article.

\section{Ethics approval}

All animal procedures and experimental protocols were approved by our local ethics committee on animal experimentation (protocol number 113/ 07). All efforts were made to minimize animal suffering and the number of animals used.

\section{Consent for publication}

Not applicable.

\section{Competing interests}

The author and co-authors declare that there are no conflicts of interest to disclose concerning the publication of this article.

\section{Author details}

${ }^{1}$ Departamento de Medicina Interna da Faculdade de Medicina da Universidade Federal do Ceará, Fortaleza, Ceará, Brazil. ²Departamento de Química Orgânica e Inorgânica da Universidade Federal do Ceará, Fortaleza, Brazil. ${ }^{3}$ Departamento de Morfologia da Faculdade de Medicina da Universidade Federal do Ceará, Fortaleza, Ceará, Brazil.

Received: 3 December 2019 Accepted: 16 April 2020

Published online: 11 May 2020

\section{References}

1. Hunter DJ. Viscosupplementation for osteoarthritis of the knee. N Engl J Med. 2015:372:1040-7

2. McAlindon TE, Bannuru RR, Sullivan MC, Arden NK, Berenbaum F, BiermaZeinstra SM, et al. OARSI guidelines for the non-surgical management of knee osteoarthritis. Osteoarthr Cartil. 2014;22:363-88.

3. Hochberg MC, Altman RD, April KT, Benkhalti M, Guyatt G, McGowan J, et al. American College of Rheumatology 2012 recommendations for the use of nonpharmacologic and pharmacologic therapies in osteoarthritis of the hand, hip and knee. Arthritis Care Res. 2012;64:465-74

4. Bruyère $\mathrm{O}$, Cooper $\mathrm{C}$, Pelletier JP, Branco J, Luisa Brandi M, Guillemin F, et al. An algorithm recommendation for the management of knee osteoarthritis in Europe and internationally: a report from a task force of the European Society for Clinical and Economic Aspects of osteoporosis and osteoarthritis (ESCEO). Seminars in Arthritis Rheumatism. 2014;44:253-63.

5. Bannuru RR, Schmid CH, Kent DM, Vaysbrot EE, Wong JB, McAlindon TE. Comparative effectiveness of pharmacologic interventions for knee osteoarthritis: a systematic review and network meta-analysis. Ann Intern Med. 2015;162:46-54. 
6. Machado RC, Capela S, Rocha FAC. Polysaccharides as viscosupplementation agents: structural molecular characteristics but not rheology appear crucial to the therapeutic response. Front Med. 2017:4:1-5.

7. Kirwan J. Is there a place for intra-articular hyaluronate in osteoarthritis of the knee? Knee. 2001;8:93-101.

8. Pasquali-Ronchetti I, Guerra D, Taparelli F, Boraldi F, Bergamini G, Zizzi F, et al. Morphological analysis of knee synovial membrane biopsies from a randomized controlled clinical study comparing the effects of sodium hyaluronate (Hyalgan) and methylprednisolone acetate (Depomedrol) in osteoarthritis. Rheumatology. 2001;40:158-69.

9. Pullman-Mooar S, Mooar P, Sieck M, Clayburne G, Schumacher HR. Are there distinctive inflammatory flares after Hylan G-F 20 intraarticular injections? J Rheumatol. 2002;29:2611-4.

10. Aydin M, Arikan M, Togral G, Varis O, Audin G. Viscosupplementation of the knee: Three cases of acute Pseudoseptic Arthritis with painful and irritating complications and a literature review. Eur J Rheumatol. 2017;4:59-62.

11. Ishikawa M, Yoshioka K, Urano K, Tanaka Y, Hatanaka T, Nii A. Biocompatibility of cross-linked hyaluronate (Gel-200) for the treatment of knee osteoarthritis. Osteoarthr Cartil. 2014;22:1902-9.

12. Cunha PL, Paula RC, Feitosa JPA. Purification of guar gum for biological applications. Int J Biol Macromol. 2007;41:324-31.

13. Castro RR, Feitosa JPA, da Cunha PL, da Rocha FAC. Analgesic activity of a polysaccharide in experimental osteoarthritis in rats. Clin Rheumatol. 2007; 26:1312-9.

14. Castro RR, Silva CM, Nunes RM, Cunha PL, de Paula RC, Feitosa JPA, et al. Structural characteristics are crucial to the benefits of guar gum in experimental osteoarthritis. Carbohydr Polym. 2016;150:392-9.

15. de Melo Leite AC, Teotonio MA, Girão VC, Lima Pompeu MM, de Melo NR, Cunha TM, et al. Meniscal transection rather than excision increases pain behavior and structural damage in experimental osteoarthritis in mice. Osteoarthr Cartil. 2014;22:1878-85.

16. Jüni P, Reichenbach S, Trelle S, Tschannen B, Wandel S, Jordi B, et al. Efficacy and safety of intraarticular hylan or hyaluronic acids for osteoarthritis of the knee: a randomized controlled trial. Arthritis \& Rheumatism. 2007:56:3610-9.

17. Berenbaum F. Osteoarthritis as an inflammatory disease (osteoarthritis is not osteoarthrosis). Osteoarthr Cartil. 2013;21:16-21.

18. Altman RD, Manjoo A, Fierlinger A, Niazi F, Nicholls M. The mechanism of action for hyaluronic acid treatment in the osteoarthritic knee: a systematic review. BMC Musculoskelet Disord. 2015;16:321.

19. Davies R, Choy E. Clinical experience of IL-6 blockade in rheumatic diseasesimplications on IL-6 biology and diseases pathogenesis. Semin Immunol. 2014;26:97-104.

20. Sawant KV, Poluri KM, Dutta AK, Sepuru KM, Troshkina A, Garofalo RP, Rajarathnam K. Chemokine CXCL1 mediated neutrophil recruitment: role of glycosaminoglycan interactions. Scientific Rep. 2016;6:33123.

21. Mortensen A, Aguilar F, Crebelli R, Di Domenico A, Frutos MJ, Galtier P, Gott D. Re-evaluation of guar gum (E 412) as a food additive. EFSA J. 2017;15: 4669-731.

\section{Publisher's Note}

Springer Nature remains neutral with regard to jurisdictional claims in published maps and institutional affiliations.

Ready to submit your research? Choose BMC and benefit from:

- fast, convenient online submission

- thorough peer review by experienced researchers in your field

- rapid publication on acceptance

- support for research data, including large and complex data types

- gold Open Access which fosters wider collaboration and increased citations

- maximum visibility for your research: over $100 \mathrm{M}$ website views per year

At $\mathrm{BMC}$, research is always in progress.

Learn more biomedcentral.com/submissions 